\title{
COEFFICIENT OF CROSS CORRELATION ANALYSIS OF KINEMATICS DURING WALKING BAREFOOT AND IN VIBRAM FIVEFINGERS ${ }^{\circledR}$.
}

\author{
Darren James ${ }^{1}$ and David Cook ${ }^{1}$ \\ ${ }^{1}$ Human Performance Centre, London South Bank University, UK.
}

\section{INTRODUCTION}

The current phenomenon of barefoot running appears to have facilitated a near market saturation of conceptual barefootrelated footwear. It is no wonder since the related literature has demonstrated favourable impact-moderating adaptations (De Clercq et al., 1994; Squadrone \& Gallozzi, 2009; Lieberman et al, 2010) and provided evolutionary (Lieberman et al. 2010) and philosophical perspectives (Oschman, 2008).

The Vibram FiveFingers ${ }^{\circledR}$ is one such concept and its efficacy has been demonstrated in the literature where external reaction forces, oxygen uptake kinetics and lower extremity kinematics have been shown to demonstrate no significant differences compared to a barefoot running (Squadrone \& Gallozzi, 2009). The kinematic variables however, were constrained to discrete sagittal plane timing events; therefore, a more robust method of discriminating between temporal kinematic changes is warranted. Such a method can be derived from the coefficient of cross correlation (CCC) ( $\mathrm{Li} \&$ Caldwell, 1999).

\section{PURPOSE OF STUDY}

Investigation of lower extremity kinematics during walking barefoot (BF), in the Vibram FiveFingers ${ }^{\circledR}$ (VIB) and a standard sports shoe (Adidas Stan Smith, SS) using a contemporary statistical approach.

\section{METHODS}

Nine female subjects performed five walking trials in each condition. Speed was normalised to the average ( $\pm 1 \mathrm{sd}$ ) of five separate barefoot trials. Kinematic data were acquired using an eight camera 3D system (Qualisys, Sweden) sampling at $240 \mathrm{~Hz}$. The data were synchronously collected with two force platforms (Kistler, UK) for the identification of foot contact. The 3D pose of the lower extremity was constructed in accordance with Collins et al. (2009). Marker trajectories were smoothed with an $8 \mathrm{~Hz}$ low-pass filter based on residual analysis and then processed in Visual 3D (C-Motion Inc., USA). A proximal anatomical frame of reference was implemented (Cardan X,Y,Z).

Sagittal and frontal plane ankle, knee and hip angular displacements were analyzed using CCC and 95\% Confidence Intervals (CI) comparing BF v SS; BF v VIB and SS $\mathrm{v}$ VIB between $0-50 \%$ of stance phase. Data were interpolated (Origin 6.0, Microcal Inc., USA) from 101 data points to 501 to increase the resolution for identification of phase change. All measures reported were from the right leg.

\section{RESULTS}

Barefoot walking demonstrated a significantly earlier phase shift in sagittal plane ankle and knee kinematics when compared to the VIB and SS (Table 1; Figure 1). There were no temporal differences evident at the hip. All sagittal waveforms showed a high degree of similarity evidenced by CCC's greater than $r \geq 0.95$. No phase shifts were observed between SS and VIB at these joints in this plane of motion (Table 1).

The similarity between waveforms in the frontal plane was particularly weak $(\mathrm{r} \leq$ 0.84 ). At the ankle, although a pronounced phase shift was observed between BF v SS 
and $\mathrm{BF} v \mathrm{VIB}$, the $95 \% \mathrm{CI}$ prevented this from being significant. At the knee however; these were significant.

\begin{tabular}{|c|c|c|c|c|}
\hline $\begin{array}{l}\text { COEFFICIENT OF CRO } \\
\text { CORRELATION }\end{array}$ & BF V SS & BF V VIB & SS V VIB & \\
\hline ANKLE X (phase shitt) & 2.20 & 0.87 & 0.00 & $* * *$ \\
\hline $95 \%$ Confidence Interval & 0.79 & 0.47 & 0.00 & \\
\hline $\operatorname{ccc}(r)$ & 0.96 & 0.98 & 0.96 & \\
\hline ANKLE Y (phase shift) & 3.16 & 0.71 & 0.00 & \\
\hline $95 \%$ Confidence Interval & 3.18 & 0.77 & 0.00 & \\
\hline $\operatorname{ccc}(r)$ & 0.67 & 0.84 & 0.79 & \\
\hline KNEE X (phase shift) & 2.36 & 0.93 & 0.00 & $* * *$ \\
\hline $95 \%$ Confidence Interval & 0.85 & 0.87 & 0.00 & \\
\hline $\operatorname{ccc}(r)$ & 0.95 & 0.98 & 0.94 & \\
\hline KNEE Y (phase shift) & 1.91 & 0.64 & 0.00 & $* * *$ \\
\hline $95 \%$ Confidence Interval & 1.21 & 0.54 & 0.00 & \\
\hline $\operatorname{ccc}(r)$ & 0.80 & 0.82 & 0.79 & \\
\hline HIP X (phase shitt) & 0.00 & 0.00 & 0.00 & \\
\hline $95 \%$ Confidence Interval & 0.00 & 0.00 & 0.00 & \\
\hline $\operatorname{ccc}(r)$ & 0.98 & 0.98 & 0.98 & \\
\hline HIP Y (phase shitt) & 0.16 & 0.16 & 0.04 & \\
\hline $95 \%$ Confidence Interval & 0.30 & 0.22 & 0.09 & \\
\hline $\operatorname{ccc}(r)$ & 0.96 & 0.97 & 0.98 & \\
\hline
\end{tabular}

Table 1. Mean $\pm 95 \%$ CI. * indicates a significant phase shift between BF v SS; ** between BF v VIB.

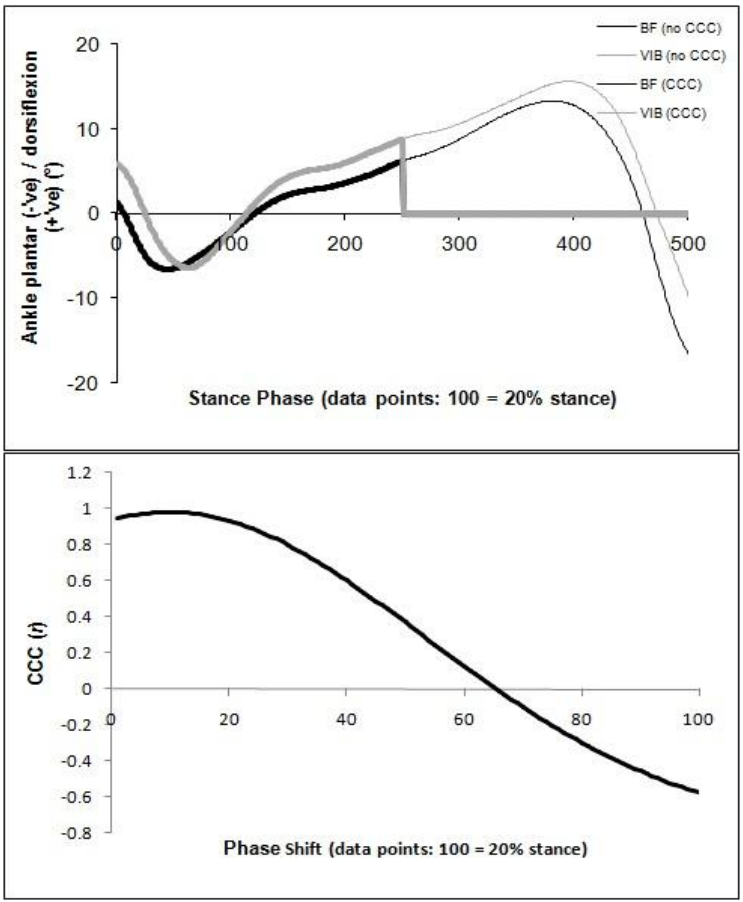

Figure 1. $\mathrm{BF} \quad \mathrm{v}$ VIB sagittal ankle kinematics $(n=1)$. Phase shift $=1.2 \%$ and $r=0.98$.

\section{DISCUSSION AND CONCLUSION}

A barefoot shoe is an oxymoron and this has been exemplified in the present study by highlighting distinct temporal differences in lower extremity kinematics during walking barefoot and in the Vibram FiveFingers ${ }^{\circledR}$. While Vibram ${ }^{\circledR}$ have engineered a shoe to resemble as close as possible a natural form, the presence of rubber cushioning cannot be overlooked as to the contributing factor which differentiates barefoot mechanics to that of footwear. Indeed, the role of the heel pad has been alluded to perform as protector rather than a shock absorber (De Clercq et al., 1994); thus subsequent kinematics must inevitably differ as load is quickly transferred from the heel to the metatarsal region in order to prevent overload (Robbins et al., 1988).

This is the challenging obstacle facing footwear manufacturers in pursuit of the barefoot 'ideal'.

\section{REFERENCES}

Collins, T. et al. (2009). Gait Posture, 30(2), 173-180.

De Clercq, D. et al. (1994). J. Biomech, 27(10), 1213-1222.

Li, L. and Caldwell, G. (1999). J.

Electromyogr. Kinesiol, 9(6), 385-389.

Lieberman, D. et al. (2010). Nature, 463(7280), 531-535.

Oschman, J. (2008). J. Bodyw. Mov. Ther, 13(3), 215-228.

Robbins, S. et al. (1988). Med. Sci. Sports Exerc, 20(1), 85-92.

Squadrone, R. \& Gallozzi, C. (2009).J. Sports med. Phys. Fitness, 49(1), 6-13. 